numbers, when the maximum occurs, and the brighter meteors, both Perseids and non-Perseids, should be individually recorded as regards their apparent paths amongst the stars and their durations of flight.

Photometric 'Tests of Spectroscopic Binaries.Mr. Joel Stebbins gives an account of his photometric tests of spectroscopic binaries (Astrophysical Journal, vol. xxxix., No. 5), and it is interesting to note that the attempt has been successful. His first experiments were made in 1904, with a visual photometer; but, not succeeding in finding any new variables, he laid the problem aside for a time. The perfection of the selenium photometer has led him to renew the tests and the results are described in his paper. Using a telescope of 12-in. aperture, he has limited himself in the first instance to stars brighter than third magnitude, and arranged his programme of binaries so as to observe them at the proper times. Then he computes from the spectroscopic elements the instants when the longitude from the node is equal to $90^{\circ}$ or $270^{\circ}$, and observes at these times. The observations are most difficult because of the exacting requirements, and only work on the very first-class nights is possible. Mr. Stebbins has considered that the most favourable cases for inquiry are the systems of shortperiod and large range of velocity, or those which have a large value for $m^{3}{ }_{2} \sin ^{3} i /\left(m_{1}+m_{2}\right)^{2}$. So far his observations have led him to discover four eclipsing stars, while sevel, other stars are considered as constant. The following table summarises his results :-

\begin{tabular}{|c|c|c|c|c|c|c|}
\hline \multicolumn{7}{|c|}{ Eclipsing Stars. } \\
\hline Star & & Period $d$ & & Spectrum & & $\begin{array}{r}m^{3} \sin ^{3} i \\
\left(m_{1}+m_{2}\right)^{2}\end{array}$ \\
\hline$\beta$.Aurigæ ... & $\cdots$ & 3.96 & $\cdots$ & Ap & $\cdots$ & 0.54 \\
\hline$\delta$ Orionis $\ldots$ & $\ldots$ & $5 \cdot 73$ & ... & Bo & $\ldots$ & 0.60 \\
\hline a Virginis & $\cdots$ & 4.01 & $\ldots$ & $\mathrm{B} 2$ & $\ldots$ & 0.82 \\
\hline Coronæ ... & $\cdots$ & $17: 36$ & $\cdots$ & Ao & ... & 0.06 \\
\hline \multicolumn{7}{|c|}{ Constant Stars. } \\
\hline a Andromedæ & $\cdots$ & $96 \cdot 67$ & $\ldots$ & Ao & $\ldots$ & 0.18 \\
\hline a Aurigæ ... & $\ldots$ & 102.02 & $\ldots$ & Go & $\ldots$ & $0 \cdot 18$ \\
\hline 2 Orionis ... & $\ldots$ & $29 \cdot 14$ & ... & $\mathrm{Oe}_{5}$ & $\ldots$ & $I \cdot I_{4}$ \\
\hline$a_{1}$ Geminorum & $\ldots$ & $2 \cdot 93$ & $\cdots$ & Ao & $\ldots$ & 0.0097 \\
\hline$a_{2}$ Geminorum & $\ldots$ & $9 \cdot 22$ & $\ldots$ & Ao & $\ldots$ & 0.0075 \\
\hline$\zeta$ Ursæ Majoris & & $20 \cdot 54$ & $\ldots$ & Ap & $\ldots$ & 0.49 \\
\hline$\beta$ Scorpii ... & & 6.83 & $\ldots$ & $\mathrm{BI}$ & $\ldots$ & $1 \cdot 26$ \\
\hline
\end{tabular}

Latitude Variation I9I3.0 To I9I4.0.-Prof. A1brecht communicates to the Astronomische Nachrichten, No. 4749 , provisional results of the International Latitude Service for the period I9r3.0 to I914.0. The information is presented in a form similar to those previously published, and so is familiar to readers of this column. Since I9I2 the amplitude of variation has become rapidly reduced. A useful diagram accompanies the communication displaying graphically the track of the pole from 1909.0 to the beginning of the present year.

A Close Companion to $\eta$ Argus.-Mr. R. T. A. innes publishes in the Monthly Notices for June (vol. 1xxiv., No. 8, p. 697) some details about the magnitude of $\eta$ Argus and the discovery of a close companion. The former observations were made as it was reported that this star had become a naked eye object in Igr3, but it is shown here that since 1899 the magnitude ( $7 \cdot 7$ about) has not changed, no variation greater than the errors of estimation being detected. On June ro Mr. Innes found that $\eta$ Argus was not a single star, but had a faint companion north following ( $74^{\circ}, I^{\prime \prime}$, mags. about 8.0 and 10.5$)$. Mr. Innes recalls an observation of his made in rgoo, when he found the star single, and he refers to Prof. See's unsuccessful search in 1897 for duplicity. Thus he concludes that there is a fair a priori probability that the companion is in orbital movement, and suggests that the outbursts of light which have occurred in the past have been caused by periastral grazings. Two other observers corroborated the presence of this companion, and it was further noticed at the same time that $\eta$ Argus appeared fuzzy, it being impossible to focus this star sharply while neighbouring stars of much the same hue, as well as those both redder and yellower, could be sharply focussed.

\section{RELICS OF A LOST CULTURE IN ARIZONA.}

D. J. WALTER FEWKES gives a detailed and fully-illustrated account of his archæological investigations of the Casa Grande, and in the Upper Verde River and Walnut Creek valleys, Arizona, in the Twenty-eighth Annual Report of the Bureau of American Ethnology, rgo6-7 (I912). Immediately after the discovery of Casa Grande by Father Kino in 1694 , there arose a legend, which became persistent, that it was one of the halting-places of the Aztec on their way south. There is, however, no evidence to connect the inhabitants of this building with any of the tribes of the Mexican plateau.

The ruins consist of four compounds and several "clan houses." The compounds are surrounded by a rectangular wall and contain numerous buildings; in one there is a large castle-like building, the Casa Grande. The builders evolved two distinct types of architecture : (I) "great houses," with thick walls, apparently constructed by - many persons-features which point to these structures as devoted to public purposes; (2) one-room habitations with wattle walls, provided with a central fire-place in the floor, and with a doorway in the middle of one of the long sides. The presence of stone idols (of which many are figured) indicates a well-developed ceremonial system. While the inhabitants possessed effective weapons in the form of spears and bows and arrows, they were essentially agricultural, cultivating fields of maize, and possibly beans, squashes, and the like. They also gathered mesquite beans. They wove various fibres into coloured belts and cloth, and raised cotton. They made basketry and unglazed pottery, which they decorated with symbols. In disposing of their dead they practised both cremation and inhumation.

Dr. Fewkes concludes that the whole drainage system of the Gila river was inhabited by an agricultural people in a homogeneous stage of culture. Throughout this region existed minor divisions of a common stock. The Pima name Hoholam, or Ancients, may be adopted to designate this ancestral stock, to whom may be ascribed the erection of the casas grandes on the Gila. These "great houses" were places of refuge, ceremony, and trade. They were inhabited by, and ruled by, chiefs, whose names are known to the present Pima. The people lived in small huts of perishable character, not unlike the Pima jacales of historic times. In the course of time a hostile faction bent on pillage came into this region from the east and west and drove the agriculturists out of their casas grandes, or, at least, broke up the custom of building such structures. But, although dispersed, the ancient house builders were not exterminated; some of them became refugees and migrated south into Mexico, some followed the course of the Verde and the Tonto into the northern mountains; but others, perhaps the majority, gradually lost their former culture, and remained in the Gila valley, becoming the ancestors of the present Pima, Papago. and Kwahadt (Quahatika). Those who went northward later built pueblos, now in ruins, in the Little Colorado valley. Their descendants ultimately joined NO. 2335, VOL. 93] 
the Zuñi and the Hopi, according to their legends, with whom they still live.

Although Dr. Fewkes refers to the Hohokam as being "homogeneous," the fact that they practised two forms of burial would lead one to suppose a mixture of two cultures. He also points out that whereas the Hohokam dwellings were rectangular, those of the Pima are circular in form, but some of the Pima houses are rectangular; also the Pima do not burn their dead. Dr. Fewkes concludes by saying: "In considering the prehistoric migrations of agricultural peoples in the south-west, especially with respect to changes in culture and to diminution of population, we must not lose sight of the influence of increased salinity due, directly or indirectly, to long-continued prehistoric irrigation. This cause was perhaps more effectual than human enenies or increased aridity [as Ellsworth Huntingdon claims] in breaking up the pre. historic culture. If barrenness of the soil, due to the
This new base was measured near the town of Lossiemouth, on the southern shore of Moray Firth, and the operations have been described in Professional Paper, No. I, I9I2, where the probable error of the final value is given as $I$ in 900,000 . The original triangulation was computed in terms of the $10-\mathrm{ft}$. standard bar of the Ordnance Survey, and a useful chapter of this paper places on record the relations between this bar, the French legal metre, and the international metre of the Bureau International des Poids et Mesures. The three stations-Corriehabbie, Mormon Hill, and Knock of Grange--in the principal triangulation were selected near the Lossiemouth base for the work of verification; but some difficulty was experienced on account of the observation points not having been marked originally in as permanent a manner as is now employed, wooden pickets having been used. All triangulation points that are now being occupied and those of the test triangulation are

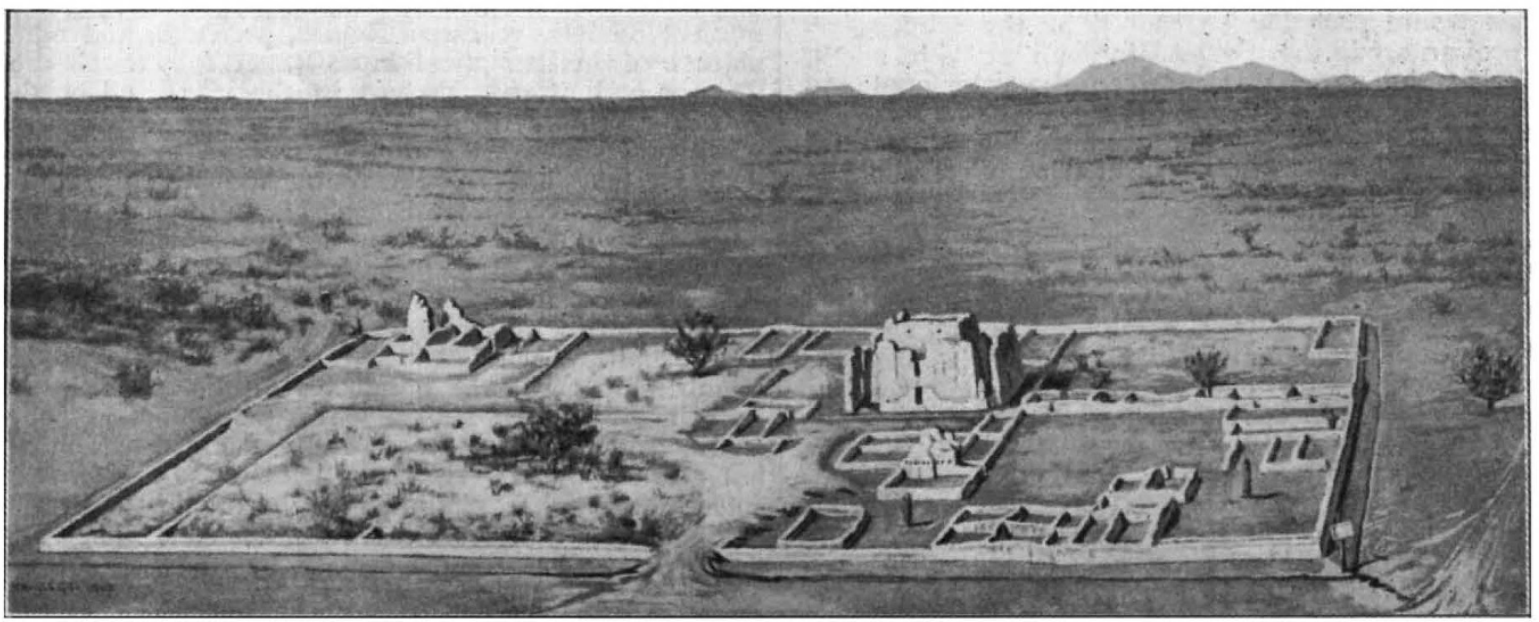

Bird's-eye view of Compound A, from the east.

cause mentioned, led to the abandonment of populous aboriginal compounds, this fact has an important bearing on the future of the white farmers in the Gila and Salt River valleys."

A. C. HADDON.

\section{THE PRINCIPAL TRIANGULATION OF THE UNITED KINGDOM.1}

THIS publication of the Ordnance Survey deals with a subject of especial interest, since it sets forth the operations which were undertaken in roro, I9II, and I9I2, in order to test the accuracy of a portion of the principal triangulation of the United Kingdom, and discusses the results obtained. This triangulation, which was observed during the seventytwo years, $1783-1855$, comprises $55^{2}$ triangles, and the mean error of an angle as given by Ferrero's formula, $\mathrm{M}=\sqrt{\frac{\Sigma \Delta^{2}}{3 n}}$ is $\pm \mathbf{r} \cdot 8^{\prime \prime}$, a value which is somewhat larger than that of recent first order triangulation. This raised the question whether the triangulation was suitable for incorporation with recent Continental geodetic work. It was therefore decided to measure a new base in a part remote from the principal bases of the triangulation at Lough Foyle and on Salisbury Plain, and to re-observe a portion of the principal triangulation in its neighbourhood.

1 Ordnance Survey. Professional Papers, new series, 2. "An Investigation into the Accuracy of the Principal Triangulation of the United tion into the Accuracy of the Principal Triangulation of the United by Col. C. F. Close. Pp. 20+v plates. (London: H M. Stationery ()ffice ; Wyman and Sons, Ltd., rgr3.) Price $2 s$. marked with bronze bolts set, in rock or in a thick foundation of concrete.

The angles were measured with a r2-in. theodolite constructed for this work by Messrs. Watts and Sons, the horizontal circle being read by means of three microscopes. Eight arcs were observed, and the mean error of an angle in the twenty-nine triangles is given as $\pm 0.517^{\prime \prime}$

For marking the points to be observed both lamps and heliostats were provided, the pattern being the same as that used in the measurement of the arc of meridian in Uganda; but it was rarely possible to use the heliostats even during the exceptionally fine summer of IgII, and practically all the observations were made on lamps. The theodolite is briefly but not exhaustively described, and a detailed investigation of it would be of much interest. The readings of the horizontal circle are to single seconds, and to tenths of a second by estimation; the vertical circle is only 6 in. in diameter, and is read to one minute of arc, being merely intended for setting to any known angle of elevation.

A special plumbing telescope, which is screwed into the upper horizontal plate, and can be focussed to view marks at from $3^{-20} \mathrm{ft}$. distant, provides the means for accurately centring the instrument over the station mark. Concrete observing pillars were used at each station, and were made with a central vertical shaft over the station mark, this being illuminated through horizontal view-holes provided in the base of the pillar.

A large triangulation error which was found in the

NO. 2335, VOL. 93] 